\title{
No direct by maternal effects interaction detected for pre-weaning growth in Romane sheep using a reaction norm model
}

\author{
Ingrid David ${ }^{*}$, Frédéric Bouvier ${ }^{2}$, Edmond Ricard $^{1}$, Julien Ruesche ${ }^{1}$ and Jean-Louis Weisbecker ${ }^{3}$
}

\begin{abstract}
Background: The pre-weaning growth of lambs, an important component of meat production, depends on maternal and direct effects. These effects cannot be observed directly and models used to study pre-weaning growth assume that they are additive. However, it is reasonable to suggest that the influence of direct effects on growth may differ depending on the value of maternal effects i.e. an interaction may exist between the two components.

Methods: To test this hypothesis, an experiment was carried out in Romane sheep in order to obtain observations of maternal phenotypic effects (milk yield and milk quality) and pre-weaning growth of the lambs. The experiment consisted of mating ewes that had markedly different maternal genetic effects with rams that contributed very different genetic effects in four replicates of a $3 \times 2$ factorial plan. Milk yield was measured using the lamb suckling weight differential technique and milk composition (fat and protein contents) was determined by infrared spectroscopy at 15, 21 and 35 days after lambing. Lambs were weighed at birth and then at 15, 21 and 35 days. An interaction between genotype (of the lamb) and environment (milk yield and quality) for average daily gain was tested using a restricted likelihood ratio test, comparing a linear reaction norm model (interaction model) to a classical additive model (no interaction model).
\end{abstract}

Results: A total of 1284 weights of 442 lambs born from 166 different ewes were analysed. On average, the ewes produced $2.3 \pm 0.8 \mathrm{~L}$ milk per day. The average protein and fat contents were $50 \pm 4 \mathrm{~g} / \mathrm{L}$ and $60 \pm 18 \mathrm{~g} / \mathrm{L}$, respectively. The mean 0-35 day average daily gain was $207 \pm 46 \mathrm{~g} / \mathrm{d}$. Results of the restricted likelihood ratio tests did not highlight any significant interactions between the genotype of the lambs and milk production of the ewe.

Conclusions: Our results support the hypothesis of additivity of maternal and direct effects on growth that is currently applied in genetic evaluation models.

\section{Background}

Pre-weaning growth is a complex trait for which phenotypic observations recorded on the lamb result from effects contributed by two individuals: by the lamb via direct effects and by the mother via maternal effects. The direct effects correspond to the suckling behaviour and growth ability of the young. Maternal effects depend on the mother's ability to produce the milk required for growth and her maternal behaviour, and are strictly environmental from the perspective of the lamb [1]. Both direct and maternal effects are under genetic and environmental control.

\footnotetext{
* Correspondence: Ingrid.David@toulouse.inra.fr

'INRA UR631 SAGA, Castanet-Tolosan F-31326, France

Full list of author information is available at the end of the article
}

In the context of pre-weaning growth models, the standard assumption is that the observed phenotype is the sum of the environmental and genetic effects contributed by the ewe and its lamb [2]. In some cases, these models produce surprising results, e.g., strong negative estimates of the correlation between maternal and direct genetic effects [3,4]. Some authors have suggested that the hypothesis of additivity between direct and maternal effects may be too restrictive [5]. Experimental findings have demonstrated significant interactions between maternal and offspring genotypes in mice [6] and insects [7]. Wolf [8] gave a simple explanation of this in the case of mammals for growth performances: "...if offspring differ in how efficiently they process milk, and this difference has a genetic basis, then the contribution of the maternal character (performance

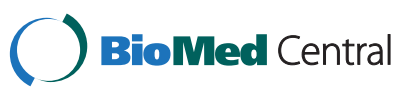


on milk production) would not be additive", or in other words, growth $=$ milk production"feed conversion efficiency. This suggests the presence of an interaction between direct and maternal effects. Our aim was to test this hypothesis in Romane sheep in order to determine whether the assumption of additivity applied in current genetic evaluation models is appropriate or not. To achieve this, we developed an experimental design in which both growth and maternal phenotypes were recorded. Using a reaction norm model, we tested for the presence of an interaction between the direct genetic effect of the lamb and the maternal phenotypes.

\section{Methods}

The experiment was carried out over a three-year period in order to obtain observations of maternal effects (milk quantity and quality) and growth records in Romane sheep. It consisted of mating ewes with markedly different maternal genetic effects (three groups: high, moderate and low maternal genetic effects) with rams that contributed very different direct genetic effects (two groups: high and low direct genetic effects) in four replicates of a $3 \times 2$ factorial plan. The measurements were performed on the lambs that resulted from these matings. Ewes and rams were selected from Romane sheep born at the INRA experimental farm La Sapinière (France) and which constitute the nucleus flock of the INRA401 composite sheep strain [9]. Estimated breeding values (EBV) based on average daily gain from 0 to 45 days (0-45 day ADG) obtained with an additive animal model (including direct and maternal effects) were used to classify the animals into different maternal and direct genetic effects groups. To obtain these EBV, data on lamb growth from 4260 multiparous Romane ewes (19 203 lambs, 294 sires) were analyzed. Random effects included in the model were correlated direct and maternal genetic effects and permanent environmental effects for the ewe and litter effects. Significant fixed environmental effects and one way interactions for age of the ewe, sex of the lamb, litter size at birth*litter size at weaning, and year*season were included also. Based on the resulting EBV, 240 multiparous ewes (2 to 3 years old) were selected: 80 with high maternal genetic effects, 80 with moderate maternal genetic effects and 80 with low maternal genetic effects. Twelve rams, six with low direct genetic effects and six with high direct genetic effects, were selected also. Animals were divided into two cohorts (named A and B), with equal numbers of animals from the direct and maternal genetic groups. During the experimental period, each ewe was mated twice (in April 2009 and April 2010 for animals in cohort A, in June 2010 and April 2011 for animals in cohort B). If the first mating of a ewe was performed with a male of the low direct genetic effects group, then the second mating was performed with a male of the high direct genetic effects group, and vice versa. The first mating of both cohorts was carried out at the La Sapinière experimental farm, after which the animals were moved to the INRA experimental farm Langlade for the second mating. Natural mating occurred after synchronization of the females by inserting a $20 \mathrm{mg}$ FGA vaginal sponge (Chronogest CR, Intervet) for 14 days, followed by injection of 300 or 400 UI PMSG (Chronogest PMSG, Intervet) just after withdrawal of the sponge.

The lambs born from these matings were separated into two groups that were, respectively, artificially reared and maternally reared. In the maternally reared group, the lambs were twin-reared indoors with their mothers in small groups of six to nine ewes (eight groups per cohort and per year) in $14.5 \mathrm{~m}^{2}$ pens. From lambing to 28 days after lambing, ewes were fed with $900 \mathrm{~g}$ hay, $2700 \mathrm{~g}$ silage and $1100 \mathrm{~g}$ concentrate. From 28 to 42 days after lambing, ewes were fed with $1200 \mathrm{~g}$ hay, $3500 \mathrm{~g}$ silage and $650 \mathrm{~g}$ concentrate. To avoid stealing of milk, lambs were placed in a small pen when ewes were fed. Lambs did not have access to their mothers' food until they were 35 days old. Lambs were weighed at birth, 15, 21, 35 and 60 days after lambing and at slaughter (between 90 and 120 days).

Milk yield was estimated using the lamb suckling weight differential technique [10] at around (depending on the date of lambing of the ewe) 15, 21 and 35 days after lambing, as follows: from 5:00 AM to 7:45 AM, lambs were separated from their mothers, then returned to the ewes and allowed to suckle and empty the udder. At 8:00 AM, they were once again separated from their mothers. At 10:30 AM, the ewes were moved to individual pens $\left(1.45 \mathrm{~m}^{2}\right)$ and the lambs were weighed prior to suckling the ewe for a short period lasting a maximum of $15 \mathrm{~min}$ (the lambs were removed from their mothers as soon as they finished suckling). The lambs were weighed again after suckling and lambs and ewes returned to separate pens. At 1:30 PM, the ewes were moved again to individual pens and the weigh-suckle-weigh procedure was carried out. After the second weighing, lambs and ewes were returned to the same pen. Milk composition was determined from samples of at least $15 \mathrm{~mL}$ collected by hand milking from both sides of the udder after a short lamb suckling period ( 2 minutes) in order to empty the cistern. The ewes and lambs were managed in the same way on the day of milk collection as on the day of milk yield evaluation. Samples were collected on days 15 and 21 at 10:30 $\mathrm{AM}$ and on day 35 after lambing at 10:30 AM and 1:30 $\mathrm{PM}$ and milk fat (MF) and protein (MP) contents were determined by infrared spectroscopy at the LIAL commercial laboratory. From day 35 postpartum, lambs were fed hay ad libitum and protein in the form of commerciallyprepared lamb creep pellets. 
Milk production records were used to define the maternal phenotypic effects of the ewes as a continuous variable. Two maternal effects were considered: milk yield per day (MY) and total milk solids (TMS), defined as TMS $=(M F+M P) * M Y$ for each of the three collection days (the mean MF and MP over the morning and afternoon were used to define milk composition on day 35). The ADG of maternally-reared lambs for the three periods (from 0 to 15,15 to 21 and 21 to 35 days) were used as the dependent variable. In order to test whether there was an interaction between direct and maternal phenotypic effects (MY or TMS), the following recursive reaction norm model with known covariate $[11,12]$ was used to analyse the data:

$$
\begin{aligned}
& M I L K=\text { age }+ \text { year }+ \text { totsex }+ \text { dam_age }+v+\varepsilon_{1} \\
& A D G=a g e+\text { year }+ \text { sex }+ \text { dam_age }+W B+L W \\
& +L S B+L W^{*} \text { age }+\beta \times M I L K+u_{\text {int }} \\
& +u_{\text {slope }} \times M I L K+\varepsilon_{2} \text {, }
\end{aligned}
$$

where $M I L K$ is $M Y$ or TMS, ADG is the ADG of the lambs for the three periods, age, year, sex, WB, $L W, L S B$, totsex, dam_age are the fixed class effects of age at weighing $(15,21$ or 35 days), year $(2009,2010,2011)$, sex of the lamb, weight of the lamb at birth $(<2.5 \mathrm{~kg},>=2.5 \mathrm{~kg}$ and $<3.5 \mathrm{~kg},>=3.5 \mathrm{~kg}$ and $<4.5 \mathrm{~kg},>=4.5 \mathrm{~kg}$ ), lag in days between milk measurement and age at weighing $([-4,4])$, litter size at birth $([2,5])$, "sex" of the litter $(1=2 \mathrm{fe}$ males, $2=1$ male and 1 female, $3=2$ males), age of the dam (2, 3 or 4 years old); $L W^{*}$ age is the interaction between age at weighing and lag time between weighing and milk measurement, $\beta$ is a regression coefficient, $v$ is the additive genetic effect of the dam, $u_{i n t}$ and $u_{\text {slope }}$ are the additive genetic effects of the lamb on the intercept and slope of the linear reaction norms with variance covariance matrix $A \otimes\left[\begin{array}{ccc}\sigma_{i n t}^{2} & \sigma_{i-s} & \sigma_{i-v} \\ \sigma_{i-s} & \sigma_{s l o p e}^{2} & \sigma_{s-v} \\ \sigma_{i-v} & \sigma_{s-v} & \sigma_{v}^{2}\end{array}\right]$, where $A$ is the additive relationship matrix, and $\varepsilon_{1}$ and $\varepsilon_{2}$ are residuals with variance covariance matrix $I \otimes\left[\begin{array}{cc}\sigma_{\varepsilon 1}^{2} & \sigma_{\varepsilon 12} \\ \sigma_{\varepsilon 12} & \sigma_{\varepsilon 2}^{2}\end{array}\right]$. Fixed effects included in the models were selected in a step-by-step descending procedure, comparing the nested models with the likelihood ratio test (alpha risk was set at 5\%). For this selection, single-trait models ignoring relationships were fitted using the mixed procedure of SAS version 8.1 [13].

The interaction between genotype of the lamb and milk production of the ewe was tested by comparing the previous recursive reaction norm model to a model that ignores the term $u_{\text {slope }} \mathrm{x}$ MILK (recursive intercept model), using the restricted likelihood ratio test $\left(\mathrm{RLRT}=-2 \log \mathrm{L}_{\text {intercept_model }}+2 \log \mathrm{L}_{\text {reaction_norm_model }}\right.$, where $\log \mathrm{L}_{\mathrm{x}}$ is the $\log$ arithm of the restricted maximum likelihood of model $\mathrm{x}$ ),. These two models were fitted using the ASReml software [14].

In the recursive intercept model, heritability for MILK was estimated as $h_{M I L K}^{2}=\frac{\sigma_{v}^{2}}{\sigma_{v}^{2}+\sigma_{\varepsilon 1}^{2}}$. The direct and maternal heritabilities for ADG were estimated as $h_{\text {direct }}^{2}=\frac{\sigma_{\text {int }}^{2}}{\sigma_{p}^{2}} \quad$ and $h_{m a t}^{2}=\frac{\beta^{2} \sigma_{v}^{2}}{\sigma_{P}^{2}}$, with $\sigma_{P}^{2}=\sigma_{\text {int }}^{2}+\sigma_{\varepsilon 2}^{2}+\beta$ $\left(2 \sigma_{\varepsilon 12}+\sigma_{i-v}\right)+\beta^{2}\left(\sigma_{v}^{2}+\sigma_{\varepsilon 1}^{2}\right)$.

\section{Results}

Heritabilities estimated with the additive model used to estimate EBV to select sires and dams for 0-45d ADG were $0.15 \pm 0.02$ and $0.07 \pm 0.02$ for direct and maternal genetic effects, respectively. The estimate of the genetic correlation between the two traits was $0.08 \pm 0.14$. The average maternal EBV for the low, medium and high maternal genetic effects group were -9.7 (standard deviation SD 4.4), 4.0 (SD 3.3) and 16.6 g/day (SD 3.5), respectively. The average direct EBV for the low and high direct genetic effects group were -14.1 (SD 8.5) and 29.1 g/day (SD 7.0), respectively.

The average fertility rate for the matings made was $79 \%$ and mean prolificacy was 2.4 lambs per ewe. There were 476 lambs in the maternally reared group (corresponding to 175 ewes, of which 71 naturally suckled their lambs during two successive years of the experiment). The average lamb mortality rate between days 0 and 60 was $2.5 \%$. Thirty-four lambs were eliminated from the analysis because they were single suckling due to the death of its full-sib and were, therefore, not representative. Furthermore, $2 \%$ of the pre/post suckling weighing data were eliminated from the analysis because their lambs did not suckle for one of the time points. The final dataset contained 1284 records on 442 lambs born from 166 ewes.

The mean ADG of the lambs over the 0-35 day period was equal to $207 \mathrm{~g} /$ day (SD 46). As expected (Table 1), the mean ADG was significantly higher in the high than in the low direct genetic effects group $(\Delta=12 \pm 4 \mathrm{~g} /$ day $)$ and in the high compared to the medium $(\Delta=16 \pm 5 \mathrm{~g} /$ day $)$ and low $(\Delta=28 \pm 5 \mathrm{~g} /$ day) maternal genetic effects group.

Summary statistics on ADG and milk production by age are in Table 2. ADG was significantly higher in the

Table 1 Mean (standard deviation) average daily gain from 0 to 35 days ( $g / d a y)$ for the direct and maternal genetic effects groups

\begin{tabular}{llllll}
\hline & \multicolumn{5}{c}{ Maternal genetic group } \\
\hline \multirow{2}{*}{ Direct genetic group } & Low & Medium & High & Total \\
& Low & $189(35)$ & $207(49)$ & $212(38)$ & $201(42)$ \\
& High & $198(53)$ & $209(43)$ & $229(47)$ & $213(49)$ \\
& Total & $193(44)$ & $205(46)$ & $221(44)$ & $207(46)$ \\
\hline
\end{tabular}


Table 2 Average daily gain (ADG) of lambs and milk production (milk yield (MY) and total milk solids (TMS)) of the ewes on three days after lambing

\begin{tabular}{llll}
\hline Day & ADG (g/day) & MY $(\mathbf{m L})$ & TMS $(\mathbf{g})$ \\
\hline 15 & $223(54)$ & $2721(734)$ & $291(83)$ \\
21 & $194(52)$ & $2358(751)$ & $253(78)$ \\
35 & $194(49)$ & $1905(752)$ & $217(84)$ \\
\hline
\end{tabular}

Standard deviations are in brackets.

0-15 day period than in the 15-21 day and the 21-35 day periods $(\mathrm{p}<0.0001)$. The average milk yield was $2.3 \mathrm{~L} /$ day (SD 0.8) and tended to decrease with age of the lambs over the 15-35 day period. There was a significant positive relationship between milk yield and the maternal genetic effects groups; the average milk yield was higher in the group with high maternal genetic effects $(2.5 \mathrm{~L} /$ day) than in the groups with moderate $(2.3 \mathrm{~L} /$ day $)$ and low maternal genetic effects $(2.2 \mathrm{~L} /$ day $)$. The average MF was $60 \mathrm{~g} / \mathrm{L}$ (SD 18) and the average $\mathrm{MP}$ was $50 \mathrm{~g} / \mathrm{L}$ (SD 4). There was no clear difference in MF and MP between the maternal genetic effects group. The average TMS was 253 g/day (SD 87), significantly different depending on the maternal genetic effect group: means of $238 \pm 5,247 \pm 5$ and $272 \pm 5$ g/day in the low, medium and high maternal genetic group, respectively. Phenotypes for MY and TMS were, of course, highly correlated $(0.90)$. The mean correlation between phenotypes for MY and ADG was 0.58 and remained quite stable with age of the lambs. The correlation between phenotypes for TMS and ADG was slightly lower (0.54).

The recursive reaction norm model with TMS as a covariate did not converge. Thus, results of models with TMS are not presented. Variance components estimated with the recursive intercept and reaction norm models with MY as covariate are in Table 3. Results of the restricted likelihood ratio test, comparing the recursive intercept and reaction norm models showed no significant interaction $\left(\mathrm{RLRT}_{\mathrm{MY}}=1.58\right)$ between direct genetic and maternal phenotypic effects. The residual variance was similar for both models $(\approx 820)$ and much lower than the phenotypic variance (2887). Heritabilities estimated for the direct and maternal effects for ADG in the intercept model were higher than estimates from the additive model that was used to select parents of the offspring: $0.34 \pm 0.04$ and $0.23 \pm 0.03$, respectively. The heritability of MY was high $0.66 \pm 0.03$. The estimated genetic correlation between direct and maternal effects was high and positive at $0.47 \pm 0.26$. The regression coefficient linking ADG to MY was similar for both models (3.9), indicating that a $0.1 \mathrm{~L} /$ day increase in MY by the mother induced a $3.9 \mathrm{~g} /$ day increase in ADG for each of her lambs.
Table 3 Estimates of parameters obtained with the recursive intercept and linear reaction norm models for average daily gain of lambs with milk yield $(d L)$ as covariate

\begin{tabular}{lll}
\hline & Intercept model & Reaction norm model \\
\hline$\Delta(-2 \log \mathrm{L})$ & 1.58 & \\
$\sigma_{\varepsilon 1}^{2}$ & 18 & 18 \\
$\sigma_{v}^{2}$ & 35 & 35 \\
$\sigma_{\varepsilon 2}^{2}$ & 824 & 818 \\
$\sigma_{\text {int }}^{2}$ & 789 & 768 \\
$\sigma_{\text {slope }}^{2}$ & & 126 \\
$\rho_{i-s}$ & & $-0.23 \pm 0.30$ \\
$\rho_{i-v}$ & $0.47 \pm 0.26$ & $0.46 \pm 0.27$ \\
$\rho_{s-v}$ & & $-0.59 \pm 0.94$ \\
$\beta$ & 3.9 & 3.9 \\
\hline
\end{tabular}

$\Delta(-2 \log \mathrm{L})$ : restricted likelihood ratio test $=-2 \log \mathrm{L}_{\text {intercept } \_ \text {model }}+$ $2 \log \mathrm{L}_{\text {reaction_norm_model. }} \sigma_{\varepsilon 1}^{2}, \sigma_{\varepsilon 2}^{2}, \sigma_{v}^{2}, \sigma_{\text {int }}^{2}, \sigma_{\text {slope }}^{2}$ are the variances of the residuals for MY and ADG, of the additive genetic effect of the dam on MY, of the additive genetic effects of the lamb on the intercept and slope of the linear reaction norms, respectively. $\rho_{i-s}, \rho_{i-v,} \rho_{s-v}$ are the correlations between intercept and slope, intercept and maternal effects, slope and maternal effects. $\beta$ is the regression coefficient.

\section{Discussion}

The mean prolificacy rate observed during our experiment was higher than that reported in Romane sheep by the French national recording scheme in 2010 (1279 ewes with a mean prolificacy rate after female synchronization equal to 2.13), in part because national records include younger females. Lamb mortality in the naturally-reared group (2.5\%) was lower than that reported for the Romane breed in France (6\%) but within the same range as that reported by another study in Scottish Blackface sheep [15]. Average growth rate was in line with that reported for the breed (French national recording scheme).

The objective of this study was to test whether an interaction exists between direct genetic and maternal phenotypic effects affecting ADG, given that these two components cannot be observed in practice. Environmental sensitivity to unobservable environmental factors can be analysed using a reaction norm model with an unknown covariate (RNUC). Different approximations [16] or ad-hoc procedures [17] have been reported to account for unknown covariates in reaction norm models. In RNUC, estimation of covariance functions is very sensitive to the data structure (number of animals per environment and connectedness between environments) [18]. Furthermore, Shariati et al. [19] demonstrated that the variance of the environmental effects is not identifiable if there is not at least one pair of unrelated animals in the same environment, which does not occur for preweaning growth, except with cross-fostering. For these reasons, we did not use RNUC to test for an interaction of direct with maternal effects but designed an experiment 
to obtain observations of the environmental effects contributed by the dam.

The experimental approach used is valid only if we are confident in the measurements of maternal effects obtained, i.e. that they are not biased. We evaluated milk yield using the weigh-suckle-weigh method. Since it had been shown that there is a positive correlation (0.86) between milk yield estimates obtained over a full $24 \mathrm{~h}$ period and those derived from a $12 \mathrm{~h}$ period [20], we extrapolated the daily yield using a $6 \mathrm{~h}$ test period for experimental convenience, similar to what has been done by other research groups [21]. It is acknowledged that the weigh-suckle-weigh method tends to underestimate milk yield, for several reasons: a lamb may not be able to consume all the milk available during a short period of suckling [10], a disturbance of normal suckling behaviour on the day of the test may induce a reduction in milk intake by the lamb [22] or inhibit milk release by the ewe [23], and the weight increment may be underestimated due to the voiding of faeces and urine [22]. In order to limit such underestimation, milk yield was only estimated in ewes rearing two lambs to ensure that all available milk was consumed, and the ewes and lambs were trained to be separated and grouped several times during the day. The excretion of faeces or urine between two successive weighings was recorded during a test of the weighing method and the proportion of such events was found to be small (less than $8 \%$ of the lambs). Also, underestimation of milk yield is not a problem in our case since it is a non-differential bias that does not affect the ranking of the ewes for milk yield. To obtain a more accurate measurement of milk production, one solution might be to make a third mating and to collect milk from the ewe by a milking machine throughout lactation (assuming that lactation remains stable with age). Milk production adjusted for the number of lambs born then corresponds to a maternal effect if there is no difference between ewes regarding how they accept the constraint of machine milking. However, milking is a difficult task in meat sheep.

To test the presence of an interaction between direct and maternal effects, we used a linear reaction norm model. Higher-order polynomials were tested but the models failed to converge. In the literature, reaction norm models with significant higher order terms are exceptions $[24,25]$. To take the relationship between ADG and milk yield into account, we used a recursive model, which assumed that milk yield of the ewe affected ADG of the lamb but that ADG had no effect on milk yield. Some authors have considered a simultaneous relationship between ADG and average daily feed intake [26]. This positive feedback of ADG on milk yield may not occur in our case because, as explained previously, twin rearing should insure that the maximal milk production potential of the ewe is reached regardless of the ADG of the lambs. The estimate of heritability for milk yield was higher than has been reported in the literature for dairy sheep [27]. Estimates of heritabilities for direct and maternal effects for ADG from the reaction norm model were also higher than reported in the literature [28] and than estimated with the additive linear model that was used to select parents of the offspring. Higher heritabilities can be explained by the selection of parents and the more controlled environment in which the study took place in comparison with field data which is confirmed by the lower ratio of the residual variance to the phenotypic variance observed on our experimental data in comparison with field data (0.28 versus 0.46). Furthermore, our reaction

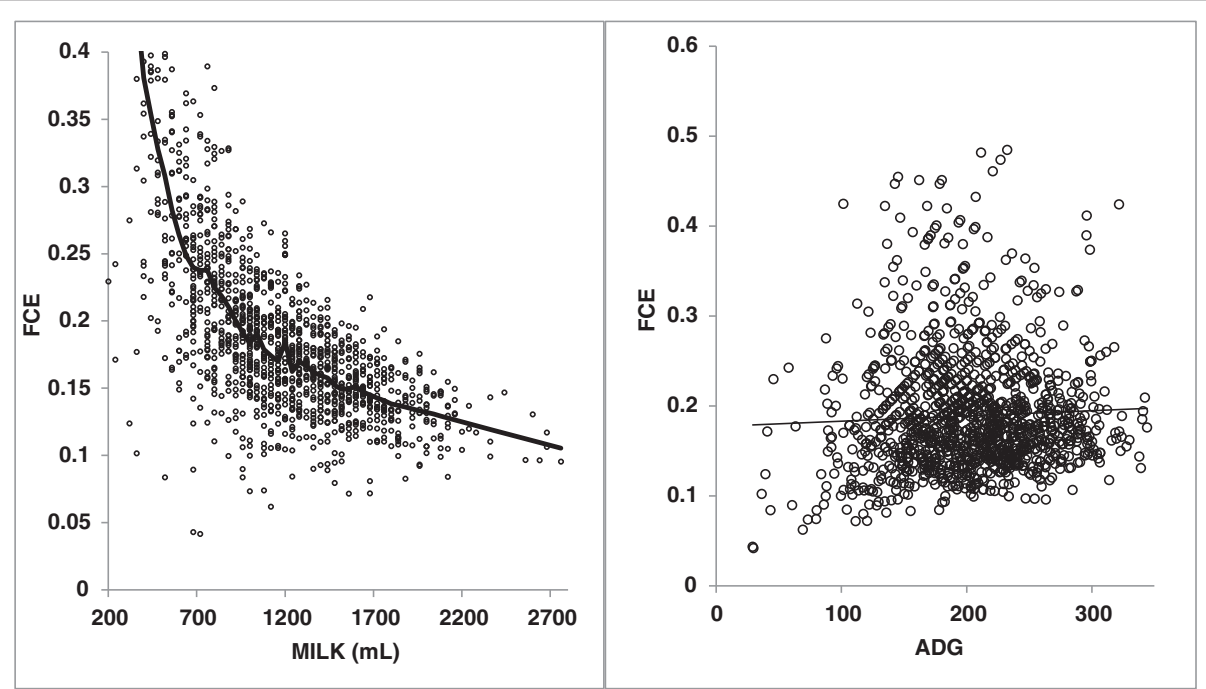

Figure 1 Change in feed conversion efficiency ( $F C E=$ milk consumed per day/average daily gain) with milk yield (MY) and average daily gain (ADG). 
norm model did not include a permanent environmental effect of the lamb (the model did not converge for that case) to take repeated measurements into account, which could also have contributed to overestimation of the heritability. For MY, the permanent environment of the ewe was not included in the model because its variance was not significantly different from 0 . Our estimate of the genetic correlation between direct and maternal effects was in the range of those obtained in previous studies, which varied from -0.52 [29] to +0.52 [30].

Contrary to what was expected, we were not able to identify a significant interaction between direct effects and milk production using the reaction norm model. A first explanation for the discrepancy between our findings and our interpretation of the physiological equation (growth $=$ feed conversion efficiency"milk consumption"milk quality (physiology) $\Leftrightarrow$ growth $=$ direct effects* milk consumption"milk quality (interpretation)) could be that our test had insufficient power because, although parents were chosen based on extreme direct or maternal genetic effects, the genetic difference between direct effects for lambs or between milk productions of the ewes was not sufficiently large. A second explanation is that our interpretation of the physiological equation is correct but the feed conversion efficiency (FCE) varied with the milk consumed differently depending on the genotype of the lamb in such a way that it eliminated an interaction between direct effects of the lamb and milk production. The corresponding model for ADG of animal $i$ in (milk) environment $j$ could be the following (ignoring other environmental effects for the sake of simplicity): $A D G_{i j}=$ $\left(\mu_{F C E}+u_{i j}\right) M Y_{j}+\varepsilon_{i j}$ (model 1$)$ where $u_{i j}$ is the direct genetic effect of animal $i$ in environment $j$ and $\mu_{F C E}$ is the mean feed conversion efficiency. If $u_{i j}=\frac{u_{i}}{M Y_{j}}$ then model 1 becomes $A D G_{i j}=\mu_{F C E} M Y_{j}+u_{i}+\varepsilon_{i j}$, which is a model with no interaction between direct and maternal effects. Change in feed conversion efficiency with change in feed intake has been reported in the literature [31-34]. In our case, we observed that the FCE decreased with the quantity of milk consumed and was not correlated with ADG (Figure 1). Nonetheless, we found no strong evidence in the literature indicating that the effect of feed intake on FCE differs depending on the genotype of the animals considered. To confirm this hypothesis, it would be interesting to evaluate the FCE of lambs with different genotypes when they are artificially reared with different controlled quantities of milk available each day. We plan to conduct this experiment in the near future on the experimental farm of Langlade (France).

\section{Conclusions}

This experiment, conducted over a three-year period with a large number of animals, made it possible to obtain information on the milk production and consumption of Romane sheep which, to our knowledge, has not been reported in the literature. The aim of this study was to measure direct genetic and maternal phenotypic effects to test for the existence of an interaction between them. We were not able to highlight any interactions between the direct and maternal effects in this experiment, which supported the hypothesis of additivity used in genetic evaluation models.

\section{Competing interests}

The authors declare that they have no competing interests.

\section{Authors' contributions}

ID conceived and designed the experiments, performed statistical analysis and wrote the manuscript. ER set up the tools for data capture. JR validated the data. FB, JLW were responsible for recording data. All authors read and approved the final manuscript.

\section{Acknowledgments}

The authors would like to thank the French Ministry of Agriculture for its support for this study in the context of a DIREMAT Action and the LIAL commercial laboratory for its efficient assistance.

\section{Author details}

${ }^{1}$ INRA UR631 SAGA, Castanet-Tolosan F-31326, France. ${ }^{2}$ INRA UE0332

Domaine de la Sapinière, Osmoy F-18390, France. ${ }^{3}$ INRA UE0065 Domaine de Langlade, Montgiscard F-31450, France.

Received: 9 April 2013 Accepted: 11 September 2013

Published: 30 September 2013

\section{References}

1. Willham RL: The role of maternal effects in animal breeding. 3 . Biometrical aspects of maternal effects in animals. J Anim Sci 1972, 35:1288-1293.

2. Willham RL: The covariance between relatives for characters composed of components contributes by related individuals. Biometrics 1963, 19:18-27.

3. Robinson DL: Estimation and interpretation of direct and maternal genetic parameters for weights of Australian Angus cattle. Livest Prod Sci 1996, 45:1-11.

4. Koerhuis ANM, Thompson R: Models to estimate maternal effects for juvenil body weight in broiler chickens. Genet Sel Evol 1997, 29:225-249.

5. Foulley $\mathrm{J}$, Lefort $\mathrm{G}$ : Méthode d'estimation des effets directs et maternels en sélection animale. Ann Genet Sel Anim 1978, 10:475-496.

6. Cowley DE, Pomp D, Atchley WR, Eisen EJ, Hawkins-Brown D: The impact of maternal uterine genotype on postnatal growth and adult body size in mice. Genetics 1989, 122:193-203.

7. Wiklund C: The evolutionary relationship between adult oviposition preferences and larval host range in papilio machaon L. Oecologia 1975, 18:185-197.

8. Wolf JB: Indirect genetic effects and gene interaction. In Epistasis and the evolutionary process. Edited by Wolf JB, Brodie ED III, Wade MJ. New York: Oxford University Press; 2000:158-176

9. Ricordeau G, Tchamitchian L, Brunel JC, François D: La race ovine INRA 401: un exemple de souche synthétique. In INRA Prod Anim Eléments de Génétique Quantitative et Application aux Populations Animales. Hors série; 1992:255-262.

10. Doney JM, Peart JN, Smith WF: A consideration of the technique for estimation of milk yield by suckled sheep and a comparison of estimates obtained by two methods in relation to the effect of breed, level of production and stage of lactation. J Agric Sci 1979, 92:123-132.

11. Lynch M, Walsh JB: Genetics and Analysis of Quantitative Traits. Sunderland: Sinauer Associates, Inc.; 1998.

12. Gianola D, Sorensen D: Quantitative genetic models for describing simultaneous and recursive relationships between phenotypes. Genetics 2004, 167:1407-1424. 
13. SAS Institute Inc:: SAS/STAT ${ }^{\oplus}$ Software version8. Cary, NC: SAS Institute Inc; 1999.

14. Gilmour AR, Gogel BJ, Cullis BR, Welham SJ, Thompson R: ASRemI User Guide Release 1.0. Hemel Hempstead: VSN International Ltd; 2002.

15. Sawalha RM, Conington J, Brotherstone S, Villanueva B: Analyses of lamb survival of Scottish Blackface sheep. Anim Behav 2007, 1:151-157.

16. Kolmodin R, Strandberg E, Madsen P, Jensen J, Jorjani H: Genotype by environment interaction in Nordic dairy cattle studied using reaction norms. Acta Agric Scand A-AN 2002, 52:11-24.

17. Su G, Madsen P, Lund MS, Sorensen D, Korsgaard IR, Jensen J: Bayesian analysis of the linear reaction norm model with unknown covariates. J Anim Sci 2006, 84:1651-1657.

18. Calus MP, Bijma P, Veerkamp RF: Effects of data structure on the estimation of covariance functions to describe genotype by environment interactions in a reaction norm model. Genet Sel Evol 2004, 36:489-507.

19. Shariati MM, Korsgaard IR, Sorensen D: Identifiability of parameters and behaviour of MCMC chains: a case study using the reaction norm model. J Anim Breed Genet 2009, 126:92-102.

20. Ricordeau G, Boccard R, Denamur R: Mesure de la production laitière des brebis pendant la période d'allaitement. Ann Zootech 1960, 9:97-120.

21. Snowder GD, Glimp HA: Influence of breed, number of suckling lambs, and stage of lactation on ewe milk production and lamb growth under range conditions. J Anim Sci 1991, 69:923-930

22. Coombe JB, Wardrop ID, Tribe DE: A study of milk production of the grazing ewe, with emphasis on the experimental technique employed. J Agric Sci 1960, 54:353-359.

23. Owen JB: A study of the lactation and growth of hill sheep in their native environment and under lowland conditions. J Agric Sci 1957, 48:387-412.

24. Calus MP, Veerkamp RF: Estimation of environmental sensitivity of genetic merit for milk production traits using a random regression model. J Dairy Sci 2003, 86:3756-3764.

25. Pollott GE, Greeff JC: Genotype x environment interactions and genetic parameters for fecal egg count and production traits of Merino sheep. $J$ Anim Sci 2004, 82:2840-2851.

26. Cai W, Casey DS, Dekkers JCM: Selection response and genetic parameters for residual feed intake in Yorkshire swine. J Anim Sci 2008, 86:287-298.

27. Rupp R, Lagriffoul G, Astruc JM, Barillet F: Genetic parameters for milk somatic cell scores and relationships with production traits in French Lacaune dairy sheep. J Dairy Sci 2003, 86:1476-1481.

28. Safari E, Fogarty NM, Gilmour AR: A review of genetic parameter estimates for wool, growth, meat and reproduction traits in sheep. Livest Prod Sci 2005, 92:271-289.

29. Mousa E, Van Vleck LD, Leymaster KA: Genetic parameters for growth traits for a composite terminal sire breed of sheep. J Anim Sci 1999, 77:1659-1665

30. Bromley CM, Snowder GD, VanVleck LD: Genetic parameters among weight, prolificacy, and wool traits of Columbia, Polypay, Rambouillet, and Targhee sheep. J Anim Sci 2000, 78:846-858.

31. Karim SA, Santra A, Sharma VK: Growth performance of weaner lambs maintained on varying levels of dietary protein and energy in the preweaning phase. Asian-Aust J Anim Sci 2001, 14:1394-1399.

32. Arthur PF, Archer DJ, Johnston DJ, Herd RM, Richardson EC, Parnell PF: Genetic and phenotypic variance and covariance components for feed intake, feed efficiency, and other postweaning traits in Angus cattle. J Anim Sci 2001, 79:2805-2811.

33. Crowley JJ, McGee M, Kenny DA, Crews DH, Evans RD, Berry DP: Phenotypic and genetic parameters for different measures of feed efficiency in different breeds of irish performance tested bulls. J Anim Sci 2010, 88:885-894.

34. Schenkel FS, Miller SP, Wilton JW: Genetic parameters and breed differences for feed efficiency, growth, and body composition traits of young beef bulls. Can J Anim Sci 2004, 84:177-184.

doi:10.1186/1297-9686-45-37

Cite this article as: David et al:: No direct by maternal effects interaction detected for pre-weaning growth in Romane sheep using a reaction norm model. Genetics Selection Evolution 2013 45:37.

\section{Submit your next manuscript to BioMed Central and take full advantage of:}

- Convenient online submission

- Thorough peer review

- No space constraints or color figure charges

- Immediate publication on acceptance

- Inclusion in PubMed, CAS, Scopus and Google Scholar

- Research which is freely available for redistribution 